\title{
Effects of soothing music on labor pain among Filipino mothers
}

\author{
Leodoro J. Labrague, Rheajane A. Rosales, Gilbey L. Rosales, Gerald B. Fiel \\ College of Nursing \& Health Sciences, Samar State University, Philippines \\ Correspondence: Leodoro J. Labrague. Address: College of Nursing \& Health Sciences, Samar State University, \\ Philippines. Email: Leo7_ci@yahoo.com
}

Received: January 6, 2013

Accepted: February 19, 2013

Online Published: February 22, 2013

DOI : $10.5430 /$ cns.v1n1p35

URL: http://dx.doi.org/10.5430/cns.v1n1p35

\section{Abstract}

Background: Labor pain is the most undesirable and unpleasant aspect of labor experience during childbirth. In the Philippines, especially in government hospitals, they seldom receive pharmacologic and non-pharmacologic management to reduce pain. Thus, the purpose of this study was to identify the effect of soothing music on the perception of pain during the latent phase of labor among laboring women in a government hospital.

Methodology: A quasi-experimental design with random assignment was utilized in this investigation. Fifty subjects were assigned into either music $(n=25)$ or non-music group $(n=25)$. Participants' levels of pain were measured utilizing the visual analogue scale (VAS) for pain and the behavioral rating scale (BRS) for pain at two time period. The non-music group was provided with the usual standard routine of care while the music group was provided with the usual standard routine of care and was exposed music therapy for 30 minutes.

Results: Findings revealed that those in the music group had statistically significant reduction in reported pain levels compared to those in the non-music group [VAS $(t=7.317, p<0.05)$ and BRS $(t=8.128, p<0.050)$ ].

Conclusion: The finding provides promising result that soothing music during the latent phase of labor provides pain reduction and can be used as part their routine when providing care for women during this stage.

\section{Key words}

Labor pain, Music therapy, Analogue visual scale, Behavioral rating scale

\section{Introduction}

Labor pain is part of a normal process. Although expected during labor process, it is considered as the most undesirable and unpleasant aspect of the labor experience during childbirth ${ }^{[1]}$. Laboring women often experience intense pain uterine contractions resulting in visceral pain. During descent, the fetus head exerts pressure on the mother's pelvic floor, vagina and perineum causing somatic pain transmitted to the pudendal nerve ${ }^{[2,3]}$. As woman's labor progresses, labor pain also increases especially for primiparas ${ }^{[4,5]}$. Pain during birth involves two components; the physiologic component - that which includes reception by sensory nerves and transmission to the central nervous system and the psychological component - that which involves recognizing the sensation, interpreting it as painful, and reacting to the interpretation. Compared to other types of pain, labor pain is unique in the sense that it is normal and self - limiting, can be prepared for, and ends with a baby's birth ${ }^{[6,7]}$. 
Although considered as part of a normal process and is expected during labor, pain that exceeds a woman's tolerance may have adverse physiological and psychological consequences both on the woman and her fetus. For the mother, severe labor pain increases metabolic rate and oxygen demand, increase production of catecholamines, cortisol and glucagon, causes maternal respiratory and metabolic changes, and may inhibit/slow down labor progress ${ }^{[8-10]}$. Additionally, poorly unrelieved pain lessens the pleasure of this extraordinary life event for both partners and may affect woman's response to sexual activity. Severe labor pain has been implicated also in contributing to long term emotional stress, with potential adverse consequences on maternal mental health and family relationships. For the fetus, unrelieved pain causes hypoxemia and acidosis ${ }^{[6-8]}$. In light of these adverse effects, the challenge for health care providers' remains is to reduce the pain and make labor and childbirth process as pleasant as possible by providing non pharmacologic interventions that are safe, inexpensive, lacks side effects, easy to administer, and has strong intuitive appeal.

Diverse interventions such as pharmacologic methods, acupressure, biofeedback, aromatherapy, hypnosis, relaxation techniques, breathing technique, massage, and warm shower have been used to relieve labor pain ${ }^{[2,5,34,35]}$. There is more evidence to support the efficacy of pharmacological methods, but they have more adverse effects ${ }^{[33]}$. Music therapy as non-pharmacologic intervention has been studied and is believed to restore, maintain, and improve emotional, physiological and psychological well being and has been used as an adjunct to nursing practice. Music therapy has long history dating back to the time of Florence Nightingle. Nightingle utilized music as a therapeutic intervention to maintain comfort and promote healing ${ }^{[11]}$. Music as an intervention has been used on different patient populations, in a variety of conditions, means and diverse settings, primarily to reduce pain and induce relaxation, thus promoting overall sense of well being of the individual ${ }^{[12,13]}$. However, the application of music in pain management has gained popularity in medicine only in the last two decades only ${ }^{[14]}$ particularly in the treatment of psychological variables during pregnancy, and to facilitate the birthing process ${ }^{[15]}$. Listening to music causes distraction and diverts feelings of anxiety, and activates the release of endorphins-the body's natural pain killers ${ }^{[11]}$.

International studies have shown that soothing music is effective in reducing distress, pain and for inducing relaxation and reducing anxiety of the women during the latent phase of labor ${ }^{[16-23]}$. Previous studies also cited that listening to music provided greater relaxation, assisted concentration, and shortened labor ${ }^{[20,21]}$. However, in the Philippines, especially in government hospitals, laboring women seldom receive pharmacologic and non-pharmacologic management to reduce pain. Furthermore, little is known in the literature highlighting the use of music in alleviating and decreasing labor pain in Filipino women. Thus, this study was conducted to determine the effect of soothing music on the perception of pain during the latent phase of labor.

\subsection{Research objective}

The aim of the study was to identify the effects of soothing music on the perception of pain during the latent phase of labor among laboring Filipino women in a government hospital.

Specifically, this investigation aimed to:

A. Compare the baseline difference of the pre-test scores of the music and non-music group utilizing two pain scales.

B. Compare the difference on the post-test scores of the music and non-music group after music intervention.

\section{Methodology}

\subsection{Research design}

A quasi-experimental design with random assignment was utilized in this study with music and non-music group. 


\subsection{Participants}

A convenience samples of fifty women (50) giving birth in a government hospital in Samar, Philippines were recruited to participate in the study. The response rate was $100 \%$. No attempts to select samples randomly were made by investigators; however inclusion criteria were set for the purpose of delimitation. Inclusion criteria were as follows; (a) gestation of 37 to 40 weeks, (b) between ages 18 to 38 years old, (c) in the latent phase of labor, (d) with no complications of pregnancy; Gestational Diabetes, Pregnancy Induced Hypertension, (e) with no hearing problem, and (f) agree and signed a consent to participate in the study. Each qualified respondent was chosen randomly and assigned randomly to two conditions either in music group or non-music group by matching technique.

\subsection{Instruments}

To gather the data needed for the investigation, the investigators used the following instruments - one demographic form and two pain measures: Visual Analogue Scale for pain (VAS) and Behavioral Rating Scale (BRS).

\subsubsection{Demographic profile}

Demographic form was composed of socio-demographic profile of the samples, which include (a) age, (b) civil status, (c) parity, (d) educational attainment, (e) family monthly income, and (f) history of pre-natal check-up. Participants were asked to indicate their answers by checking the appropriate option.

\subsubsection{Visual analogue scale}

To measure pain perception, the visual analogue scale (VAS) was utilized. It is usually presented as a $100 \mathrm{~mm}$ horizontal line on which the patient's pain intensity is represented by a point between the extremes of "no pain at all" and "worst pain imaginable. Participants were asked to indicate the amount of pain they were feeling 'right now' by marking the appropriate place on the line. Higher values indicated increased levels of pain. To measure the level of pain, the following scaling was used; 0-4 mm as no pain, 5-44 $\mathrm{mm}$ as mild pain, $45-74 \mathrm{~mm}$ as moderate pain, and $75-100 \mathrm{~mm}$ as severe pain ${ }^{[24]}$.

\subsubsection{Behavioral rating scale}

To measure objective manifestations of pain, the nurse-rated behavioral rating scale was used ${ }^{[25]}$. The Behavioral Rating Scale is used to record and observe verbal and nonverbal cues of the laboring woman who were in their latent phase of labor. It is a five-category scale used to assess present behavioral manifestations of pain: face, restlessness, muscle tone, vocalization, and consolability. Each category is scored on the 0-2 scale, which results in a total score of $0-10$. In interpreting then scores, the following scaling was used; 0 as relaxed and comfortable, 1-3 for mild discomfort, 4-6 for moderate pain, and 7-10 for severe discomfort or pain or both. The checklist will be marked by the investigators according to observed reactions made by the patients before and after the application of soothing music.

\subsection{Procedure}

The investigators sought the approval of the Health Ethics Committee of Samar State University before the actual investigation. The principal researcher obtained the signed consent form from the respondents upon agreeing to participate in the investigation. Confidentiality and anonymity of the respondents were maintained all throughout the investigation. Women who agreed to participate in the investigation were asked to complete the demographic form and were allocated randomly into music and non-music group. The intervention took place in the labor room. The non-music group was provided with the usual standard routine care (vital signs monitoring\& fetal heart tone monitoring) while the music group was provided with the usual standard routine of care and was exposed music therapy for 30 minutes during the latent phase (2-4 cm cervical dilatation). Both groups did not received analgesics or other non-pharmacologic treatments during the course of the investigation. Pain measures (VAS and BRS) were administered before and after 30 minutes of exposure to soothing music in the music group and 30 minutes after routine standard care in the non-music group during the latent 
phase (2-4 cm cervical dilatation). Two types of pre-recorded music were used in this investigation consisting of classical and nature sounds. Subjects were asked to choose music from the set of pre-selected music. The music treatment was delivered via headphones to block environment sounds that may heighten anxiety or distract participants. Participants controlled the volume of the music during the entire listening experience.

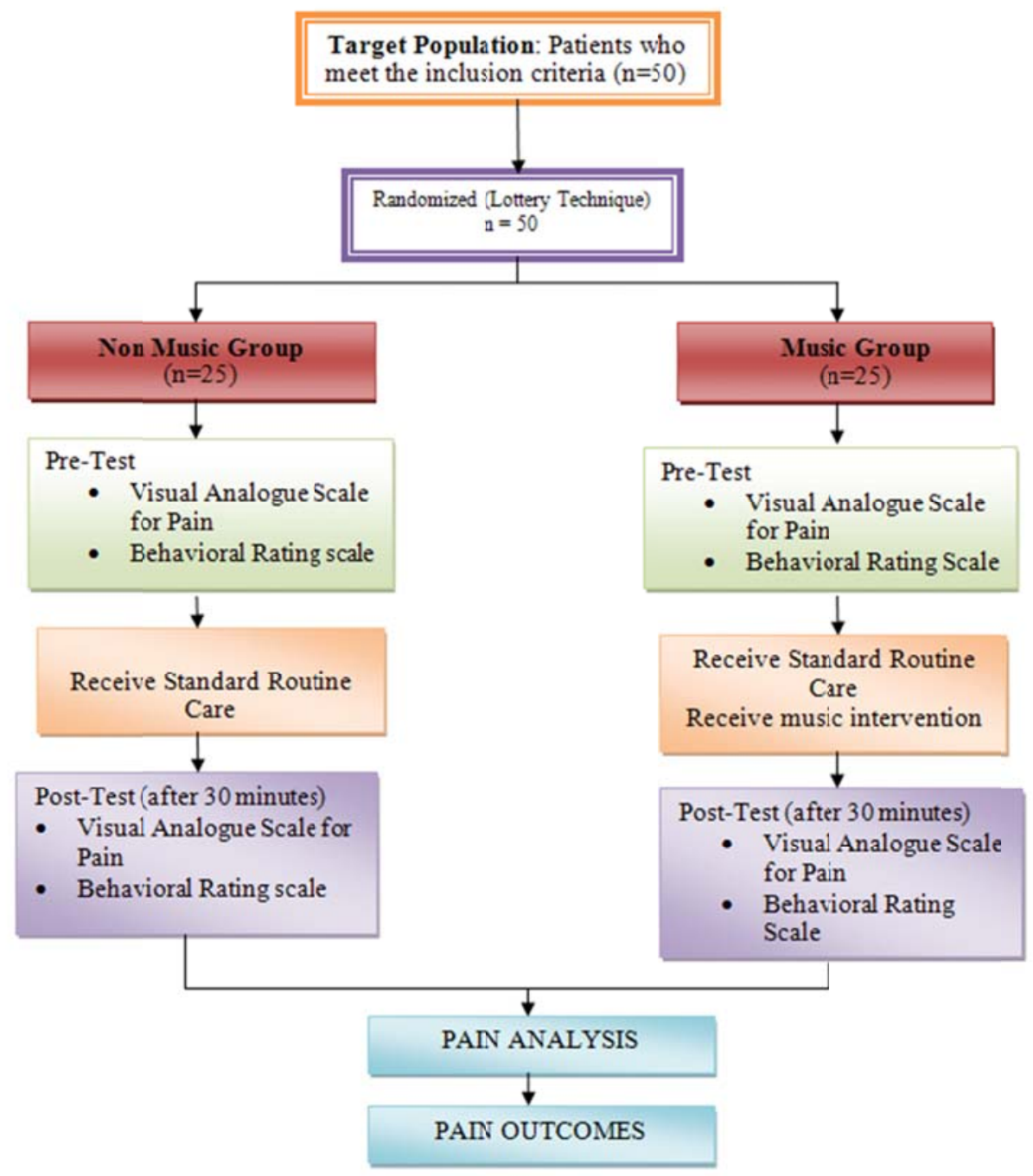

Figure 1. Study procedures

\subsection{Data analysis}

The data were entered in Microsoft Excel and were computed by SPSS version 19. Descriptive statistics used include; percentage, mean, and frequency. Chi-square and Fisher's exact test were used to determine the difference of the demographic characteristics of the subjects in both groups. Independent t-test after ensuring normality and homogeneity of 
the samples was used to detect significant difference in the baseline and post test scores. Dependent t-test was also used to identify difference in the pre-test and post test scores both in the two groups. The level of significance was set at $p<0.05$.

\section{Results}

Fifty subjects (50) were recruited to participate in the investigation. The mean age was 25.28 years with standard deviation of 4.20. More than half of the subjects in both groups were married (52\% in non-music group and $56 \%$ in music group). Meanwhile, three fourths have family income that ranges from Php 1000 to Php 5000 (84\% in non-music group and 72\% in music group). As to parity, more than half had given birth more than once (56\% in non-music group and 52\% in music group). Vast majority of the respondents received pre-natal services while pregnant (96\% in non-music group and music group). When compared, no significant differences were found on demographic data of the non-music and music group in terms of age, marital status, family monthly income, parity, and prenatal check-up.

Table1.Demographic characteristics of the subjects in two groups

\begin{tabular}{|c|c|c|c|c|c|}
\hline \multirow{2}{*}{ Characteristics } & & \multirow{2}{*}{$\begin{array}{l}\text { Non-Music group } \\
n(\%)\end{array}$} & \multirow{2}{*}{$\begin{array}{l}\text { Music group } \\
n(\%)\end{array}$} & \multirow{2}{*}{$X^{2} / t$} & \multirow{2}{*}{$p$} \\
\hline & & & & & \\
\hline \multirow[t]{4}{*}{ Age } & $18-22$ years old & $13(52)$ & $7(28)$ & \multirow[t]{4}{*}{3.633} & \multirow[t]{4}{*}{0.304} \\
\hline & $23-27$ years old & $3(12)$ & $5(20)$ & & \\
\hline & $28-32$ years old & $5(20)$ & $5(20)$ & & \\
\hline & $33-38$ years old & $4(16)$ & $8(32)$ & & \\
\hline \multirow[t]{2}{*}{ Marital status } & Single & $12(48)$ & $11(44)$ & \multirow[t]{2}{*}{0.081} & \multirow[t]{2}{*}{0.7766} \\
\hline & Married & $13(52)$ & $14(56)$ & & \\
\hline \multirow[t]{4}{*}{ Family monthly income } & PhP 1000 - 5000 & $21(84)$ & $18(72)$ & \multirow[t]{4}{*}{1.173} & \multirow[t]{4}{*}{0.630} \\
\hline & PhP 6000 - 10000 & $3(12)$ & $5(20)$ & & \\
\hline & PhP 11000 - 15000 & $1(4)$ & $1(4)$ & & \\
\hline & PhP 16000 - 20000 & $0(0)$ & $1(4)$ & & \\
\hline \multirow[t]{2}{*}{ Parity } & Primipara & $11(44)$ & $12(48)$ & \multirow[t]{2}{*}{0.081} & \multirow[t]{2}{*}{0.7766} \\
\hline & Multipara & $14(56)$ & $13(52)$ & & \\
\hline \multirow{2}{*}{$\begin{array}{l}\text { History of pre-natal } \\
\text { check up }\end{array}$} & Yes & $24(96)$ & $25(100)$ & \multirow[t]{2}{*}{1.020} & \multirow[t]{2}{*}{0.3124} \\
\hline & No & $1(4)$ & $0(0)$ & & \\
\hline
\end{tabular}

As reflected on table 2, no significant difference were found for the pre-test scores between the non-music and music group utilizing the visual analogue scale (VAS) $(t=1.3844, p=0.1728)$, however, statistically significant difference where identified when the behavioral rating scale (BRS) $(t=4.9027, p<0.05)$ was utilized.

Table 2. Baseline difference on the pre-test scores of the music and non-music group utilizing two pain scales

\begin{tabular}{|c|c|c|c|c|c|c|c|}
\hline \multirow{2}{*}{ Variables } & \multicolumn{2}{|c|}{ Non-Music group } & \multicolumn{2}{|c|}{ Music group } & \multirow{2}{*}{ Confidence interval } & \multirow{2}{*}{$t$} & \multirow{2}{*}{$\boldsymbol{P}$} \\
\hline & Mean & SD & Mean & SD & & & \\
\hline $\begin{array}{l}\text { Visual Analogue } \\
\text { Scale (VAS) }\end{array}$ & 80.33 & 12.60 & 75.20 & 13.33 & $95 \%$ (-12.59 to 2.33$)$ & 1.3844 & 0.1728 \\
\hline $\begin{array}{l}\text { Behavioral Rating } \\
\text { Scale (BRS) }\end{array}$ & 7.64 & 0.70 & 6.25 & 1.22 & $95 \%$ (0.82 to 1.96$)$ & 4.9027 & $<0.05$ \\
\hline
\end{tabular}

In the music group, comparison of the pre-test and post-test scores revealed significant difference on the VAS scores ( $t=9.915)$ and BRS scores ( $t=7.562)$. In the non-music group, no significant difference was found between the pre-test and post test scores on the VAS ( $t=1.848)$, however, significant difference was identified on the BRS scores $(t=4.706)$. 
To ascertain whether music intervention is effective in lowering labor pain, independent t-test analysis was conducted to compare whether music group did have lower pain perception than non-music group did after intervention. Women on the music group had lower scores both on VAS $(t=7.317, p<0.05)$ and BRS $(t=8.128, p<0.05)$ than the non-music group did.

Table 3. Means, standard deviations, $t$ values, and $p$ values after intervention

\begin{tabular}{|c|c|c|c|c|c|c|c|c|c|c|}
\hline \multirow[t]{3}{*}{ Variables } & \multicolumn{5}{|c|}{ Non-Music group } & \multicolumn{5}{|c|}{ Music group } \\
\hline & \multicolumn{2}{|c|}{ Pre-test } & \multicolumn{2}{|c|}{ Post-test } & \multirow[t]{2}{*}{$t$} & \multicolumn{2}{|c|}{ Pre-test } & \multicolumn{2}{|c|}{ Post-test } & \multirow[t]{2}{*}{$t$} \\
\hline & Mean & SD & Mean & SD & & Mean & SD & Mean & SD & \\
\hline $\begin{array}{l}\text { Visual Analogue } \\
\text { Scale (VAS) }\end{array}$ & 80.33 & 12.60 & 78.44 & 11.80 & 1.848 & 75.20 & 13.33 & 52.96 & 12.80 & 9.915 \\
\hline $\begin{array}{l}\text { Behavioral Rating } \\
\text { Scale (BRS) }\end{array}$ & 7.64 & 0.70 & 7.13 & 0.13 & 4.706 & 6.25 & 1.22 & 4.68 & 1.28 & 7.562 \\
\hline
\end{tabular}

Table 4. Difference on the post-test scores of the music and non-music group after intervention

\begin{tabular}{|c|c|c|c|c|c|c|c|}
\hline \multirow{2}{*}{ Variables } & \multicolumn{2}{|c|}{ Non-Music group } & \multicolumn{2}{|c|}{ Music group } & \multirow{2}{*}{ Confidence Interval } & \multirow{2}{*}{$t$} & \multirow{2}{*}{$\boldsymbol{P}$} \\
\hline & Mean & SD & Mean & SD & & & \\
\hline $\begin{array}{l}\text { Visual Analogue } \\
\text { Scale (VAS) }\end{array}$ & 78.44 & 11.80 & 52.96 & 12.80 & $95 \%$ (-32.48 to-18.48) & 7.317 & $<0.05$ \\
\hline $\begin{array}{l}\text { Behavioral Rating } \\
\text { Scale (BRS) }\end{array}$ & 7.13 & 0.13 & 4.68 & 1.28 & $95 \%(-3.05$ to -1.84$)$ & 8.128 & $<0.05$ \\
\hline
\end{tabular}

\section{Discussion}

This study identified the effect of soothing music on the perception of pain during the latent phase of labor among laboring women in a government hospital. Result of this investigation has demonstrated that soothing music is effective in decreasing pain perception among women in music group during the latent phase of labor. After exposure to music intervention, subjects in the music group reported and demonstrated reduced pain from severe to moderate level of pain. This result is in keeping with the previous studies conducted among Taiwanese ${ }^{[16]}$ and Canadian women ${ }^{[14]}$. In the study conducted by Liu et al, ${ }^{[16]}$ it was observed that compared with the non-music group, the music group had significantly lower pain and anxiety during the latent phase of labor. Browning ${ }^{[14]}$ also reported that the planned use of music by mothers and care givers enhanced prenatal preparation for birth, and was found to be an important adjunct to pain and anxiety management during labor and delivery. Meanwhile, Codding ${ }^{[20]}$ and Winocur ${ }^{[21]}$ observed less perceived pain, shorter labor, and the use of less pain medication with women for whom music was provided. Hanser, Larson, \& O’Connell ${ }^{[23]}$, and Fulton ${ }^{[17]}$ also observed that women displayed fewer pain responses during the music intervention than during the no music intervention. Phumdoung \& Good $^{[19]}$ also arrived at the same conclusion and noted that women who were exposed to soft music reported decreased both sensation and distress of active labor pain.

During labor, music may function in several ways in order to reduce pain perception. The act of listening to music may reduce the pain perception of pain as a distraction by changing the transmission of pain impulses through activating the limbic system and sensory region of the brain ${ }^{[26]}$. Moreover, music perceived by the brain may stimulate the pituitary gland to release endorphins that controls pain ${ }^{[27,28]}$. Listening to music also increases dopamine levels which contributes to the individual's experience of pleasure and motivation, which is essential to maintain a pain management regime ${ }^{[29]}$. Music is also believed to elicit emotional states and provide opportunity to process the emotions evoked by pain ${ }^{\text {[30] }}$ and also serves as an excellent stimulus for holding one's attention and directing it away from the pain ${ }^{[31]}$.

It is worth noting that reduction in pain perception was noted after listening to music utilizing two pain measures - visual analogue scale (VAS) and behavioral rating scale (BRS) after music intervention. This result strengthens the claim of 
previous authors that music may decrease or alter pain perception whether a self-report pain scale (Visual Analogue Scale/VAS) or an observer rated pain scale (Behavioral Rating Scale/BRS) is used.

Excess or poorly relived pain can be harmful in the mother ${ }^{[8-10]}$ and fetus ${ }^{[6-8]}$. Therefore, the result of this study could support the use of soothing music together with other nursing interventions in reducing the pain experienced by women during the latent phase of labor. However, it is essential to note that music intervention was administered only during the latent phase of labor, pain increases as labor progresses ${ }^{[4,5]}$ and the need for pain relief is of its greater importance. With that, further studies ascertaining whether music would still offer pain relief/reduction during the late phases maybe conducted.

While these data are important as it is the first analysis conducted in the locality, nevertheless it has some limitations. First, awareness of the aim of the intervention might have potentially affected the responses of the samples since they were informed of the purpose and the study goal before the start of the investigation. Secondly, the use of investigators-selected or predetermined music might have affected the responses to music since they were deprived from choosing music of their choice. Effects of music are enhanced when subjects appreciate the type of music ${ }^{[32]}$. Thirdly, the use of headphones rather than loudspeakers might have caused different listening experience that may impact intervention effects. Furthermore, the small sample size might have affected the statistical power and effect size of the study. Thus, future studies may be conducted to increase statistical power and effect size.

\section{Conclusions}

The results of this investigation have clearly provided promising result for the use of soothing music as an effective method of reducing pain perception among women during the latent phase of labor. As a non-pharmacological nursing intervention, music intervention is easy to administer, cost effective, harmless, do not require extra training, and appealing to the mother. Music intervention may be used by health care practitioners (medical and nursing staff, student nurses) as part of their routine when providing care with women during the labor process. The findings added knowledge to the existing body of literature on research related to non-pharmacologic management during labor and childbirth.

\section{Competing interests}

The authors declare that they have no competing interests.

\section{References}

[1] Trout KK. The neuromatrix theory of pain: implications for selected non-pharmacologic methods of pain relief for labor. Journal of Midwifery \& Women's Health. 2004; 49: 482-488. PMid:15544977

[2] Baths WW. The nature and management of labor pain: Part I. Nonpharmacologic pain relief. Am fam Physician. 2003; 68(6): 1109-1113.

[3] Brownridge P. The nature and consequences of childbirth pain. European Journal of Obstetrics and Reproductive Biology. 1995; 59: S9-S15. http://dx.doi.org/10.1016/0028-2243(95)02058-Z

[4] Cheung W, Ip WY, Chan D. Maternal anxiety and feelings of control during labour: a study of Chinese first-time pregnant women. Midwifery. 2007; 23: 123-130. PMid:17055624 http://dx.doi.org/10.1016/j.midw.2006.05.001

[5] Chang MY, Wang SY, Chen CH. Effects of massage on pain and anxiety during labour: a randomized controlled trial in Taiwan. Journal of Advanced Nursing. 2002; 38: 68-73. PMid:11895532 http://dx.doi.org/10.1046/j.1365-2648.2002.02147.x

[6] Lowe NK. The nature of labor pain. American journal of obstetrics and gynecology. 2002; 186(5), S16-S24. PMid:12011870

[7] McKinney ES, James SR, Murray SS, Ashwill JW. Maternal-Child Nursing. Second Edition. Volume I. Elsevier Saunders; 2007: 417-419.

[8] Bonica JJ, McDonald JS. The management of pain. Volume II. $2^{\text {nd }}$ edition. Philadelphia: Lea \&Febiger.1990: $1331-1343$.

[9] Blackburn ST, Loper DL. Maternal, fetal, and neonatal physiology: a clinical perspective. Philadelphia: W.B. Saunders Company; 1992. 
[10] Saisto T, Ylikorkala O, Halmesmäki E. Factors associated with fear of delivery in second pregnancies. Obstetrics \& Gynecology. 1999; 94(5, Part 1): 679-682. http://dx.doi.org/10.1016/S0029-7844(99)00413-5

[11] McCaffery R. Locsin RC. Music listening as a nursing intervention: a symphony of practice. Holistic Nursing Practice. 2002; 16(3): 70-77.

[12] Good M, Ahn S. Korean and American music reduces pain in Korean women after gynecologic surgery. Pain Management. 2008; 9: 96-103. PMid:18706380 http://dx.doi.org/10.1016/j.pmn.2008.02.002

[13] Chlan L. Effectiveness of music therapy intervention on relaxation and anxiety for patients receiving ventilator assistance. Heart and Lung. 1998; 27: 169-176. http://dx.doi.org/10.1016/S0147-9563(98)90004-8

[14] Browning CA. Using music during childbirth. Birth. 2001; 27(4): 272-276. http://dx.doi.org/10.1046/j.1523-536x.2000.00272.x

[15] McKinney C. Music therapy in obstetrics: a review. Music Therapy Perspectives. 1990; 8: 57-60.

[16] Liu YH, Chang MY, Chen CH. Effects of music therapy on labour pain and anxiety in Taiwanese first-time mothers. Journal of Clinical Nursing. 2010; 19(7-8): 1065-1072. PMid:20492051http://dx.doi.org/10.1111/j.1365-2702.2009.03028.x

[17] Fulton KB. The effects of music therapy on physiological measures, perceived pain, and perceived fatigue of women in early labor. Electronic Theses, Treatises and Dissertation. Paper 4376. 2005.

[18] Keever KJ, Shepherd P. The Use of Music in Labor: Pain Perception (No. AFIT/CI/CIA-93-004). AIR FORCE INST OF TECH WRIGHT-PATTERSON AFB OH. 1991.

[19] Phumdoung S, Good M. Music reduces sensation and distress of labor pain. Pain Management Nursing. 2003; 4(2): 54-61. http://dx.doi.org/10.1016/S1524-9042(02)54202-8

[20] Codding PA. An exploration of the uses of music in the birthing process (Doctoral dissertation, Florida State University). 1982

[21] Winokur MA. The use of music as an audio-analgesia during childbirth. Unpublished master's thesis, The Florida State University. 1984.

[22] Clark ME, McCorkle RR, Williams SB. Music therapy-assisted labor and delivery. Journal of Music Therapy. 1981; 18(2): 88-100. PMid:10252815

[23] Hanser SB, Larson SC, O'Connell AS. The effect of music on relaxation of expectant mothers during labor. Journal of Music Therapy. 1983; 20: 50-58.

[24] Katz J, Melzack R. Measurement of pain. Surg Clin North Am. 1999; 79: 231-52. http://dx.doi.org/10.1016/S0039-6109(05)70381-9

[25] Merkel SI, Voepel-Lewis T, Shayevitz JR, Malviya S. The FLACC: A behavioral scale for scoring postoperative pain in young children. Pediatric Nursing. 1997; 23(3): 293-297. PMid:9220806

[26] Kwekkeboom KL. Music versus distraction for procedural pain and anxiety in patients with cancer. Oncology Nursing Forum. 2003; 30(3): 433-440. PMid:12719743

[27] Wells C, Nown G. The Pain Relief Handbook: Self-Health Methods for Managing Pain. Firefly Books Ltd.1998.

[28] Boso M, Polito P, Barale F, Enzo E. Neurophysiology and neurobiology of the musical experience. Functional Neurology. 2006; 21: 187-191. PMid:17367577

[29] Sutoo DE, Akiyama K. Music improves dopaminergic neurotransmission: demonstration based on the effect of music on blood pressure regulation. Brain research. 2004; 1016(2): 255-262. PMid:15246862 http://dx.doi.org/10.1016/j.brainres.2004.05.018

[30] Blood AJ, Zatorre RJ. Intensely pleasurable responses to music correlate with activity in brain regions implicated in reward and emotion. Proceedings of the National Academy of Sciences. 2001; 98(20): 11818-11823. PMid:11573015 http://dx.doi.org/10.1073/pnas.191355898

[31] Brown GK, Nicassio PM, Wallston KA. Pain coping strategies and depression in rheumatoid arthritis. Journal of consulting and clinical psychology. 1989; 57(5): 652. PMid:2794186 http://dx.doi.org/10.1037/0022-006X.57.5.652

[32] Gentz BA. Alternative therapies for the management of pain in labor and delivery. Clinical obstetrics and gynecology. 2001; 44(4): 704-732. PMid:11600853http://dx.doi.org/10.1097/00003081-200112000-00010

[33] Jones L, Othman M, Dowswell T, Alfirevic Z, Gates S, Newburn M, Jordan S, Lavender T, Neilson JP. Pain management for women in labour: an overview of systematic reviews. Cochrane Database Syst Rev. 2012; 3.

[34] Lee SL, Liu CY, Lu YY, Gau ML. Efficacy of Warm showers on labor pain and birth experience during the first labor stage. Journal of Obstetric, Gynecological, \& Neonatal Nursing. 2012; 42(1): 19-28. PMid:23167574 http://dx.doi.org/10.1111/j.1552-6909.2012.01424.x

[35] Demir Y. Non-pharmacological therapies in pain management, Pain management - current issues and opinions. 2012. [Cited 2012 Jan 2] Available from:

http://www.intechopen.com/books/pain-management-current-issues-and-opinions/non-pharmacologicaltherapies-in-pain-manage ment 